\title{
BMJ Open Impact of COVID-19 lockdown on the incidence and patterns of toxic exposures and poisoning in Jordan: a retrospective descriptive study
}

\author{
Liqaa Raffee (D) , ${ }^{1}$ Hamza M Daradkeh, ${ }^{2}$ Khaled Alawneh (D) , ${ }^{3}$ Aida I Al-Fwadleh, ${ }^{4}$ \\ Moath Darweesh (D) , ${ }^{1}$ Nouran H Hammad, ${ }^{1}$ Sami A Almasarweh (D) ${ }^{1}$
}

To cite: Raffee L, Daradkeh HM, Alawneh $\mathrm{K}$, et al. Impact of COVID-19 lockdown on the incidence and patterns of toxic exposures and poisoning in Jordan: a retrospective descriptive study. BMJ Open 2021;11:e053028. doi:10.1136/ bmjopen-2021-053028

- Prepublication history for this paper is available online. To view these files, please visit the journal online (http://dx.doi org/10.1136/bmjopen-2021053028).

Received 04 May 2021 Accepted 11 November 2021

Check for updates

(c) Author(s) (or their employer(s)) 2021. Re-use permitted under CC BY-NC. No commercial re-use. See rights and permissions. Published by BMJ.

${ }^{1}$ Accidents and Emergency, Jordan University of Science and Technology, Irbid, Jordan ${ }^{2}$ Accidents and Emergency, King Abdullah University Hospital,

Ramtha, Irbid, Jordan

${ }^{3}$ Diagnostic Radiology and

Nuclear Medicine, Jordan

University of Science and

Technology, Irbid, Jordan

${ }^{4}$ Administration, Pharmacy One

Poison Center, Amman, Jordan

Correspondence to

Dr Liqaa Raffee;

laraffee5@just.edu.jo

\section{ABSTRACT}

Objectives To describe the effect of the COVID-19

lockdown in Jordan (21 March 2020-21 May 2020) on the incidence and patterns of toxic exposures and poisoning as compared with the same period from the previous year (21 March 2019-21 May 2019).

Design A retrospective descriptive study.

Methods Call data sourced from Pharmacy One Poison Center from the lockdown period (21 March 2020-21

May 2020) and the same period during 2019 (21 March

2019-21 May 2019) were revised. In addition, a database was established and analysed.

Results We noticed that not only did calls increased, but there was also a noticeable change in call patterns. Calls increased by $91 \%$ (544 vs 285 calls) during the lockdown period. Drugs were the most common among types of exposure, and the most prevalent route of exposure was ingestion. There was a notable increase in ocular exposure by $550 \%$ ( 13 vs 2 cases). The majority of exposures were at home and there were no occupational exposures. We found an increase in household cleaner exposure among males and an increase in alcohol exposure in females. Children aged below 5 years are the most affected. Even though there is an increase in the total number of cases, severe cases decreased.

Conclusion The lockdown effect on rates of toxic exposures was prominent, whether through the increase in calls or the change in patterns. As people spent more time at home, their exposure to toxic agents increased. Furthermore, cleaning recommendations led to the misuse of cleaning and disinfectant products, increasing exposures related to abating the COVID-19 infection.

\section{INTRODUCTION}

COVID-19 caused by the novel coronavirus (SARS-CoV-2) was first reported in Wuhan, China in December of 2019. ${ }^{1}$ The WHO characterised the disease as a pandemic on 11 March 2020. ${ }^{2}$ The rapid increase in the number of cases and deaths, along with the lack of vaccines and effective medical therapy, in the early course of the pandemic, has led to a global emergency response. ${ }^{34}$ Many countries adopted classic public health measures,
Article summary

The exposure patterns during COVID-19 lockdown.

- The COVID-19 lockdown effect on the numbers and patterns of exposures.

- It highlights specific exposures related to COVID-19 infection-control efforts, management protocols or self-medication.

- It highlights the important role poison control centres could play during crises.

- Information presented in this study can be taken in consideration while planning healthcare policies.

\section{Strengths and limitations of this study}

This study addresses different aspects of toxic exposures during the lockdown.

- Our data represent the majority of calls related to toxic exposures in Jordan.

- Not all exposures were reported to the poison centre.

- Poisoning specialists base their judgement and recommendations for management on the caller's information.

- It was not possible to access data from other poison centres in the country (more details on strengths and limitations were provided in the Discussion section).

including isolation and quarantine, social distancing and community containment, to slow down the spread of SARS-CoV-2. ${ }^{4-7}$ In the initial stages of the pandemic, lack of adequate information on the most effective prevention and treatment strategies allowed the spread of misinformation and resulted in the improper use of drugs, chemicals, and traditional remedies for their presumed protective or therapeutic roles even though many of these substances are known for their harmful and toxic effects. ${ }^{8-12}$

Poison centres from the USA, Canada and France reported a spike in calls related to toxic exposures during the COVID-19 
lockdown. ${ }^{13-16}$ Reported exposures included the improper use of medications, self-medication and household chemicals. ${ }^{17-19}$ However, the majority of the reported exposures were related to hand sanitisers, disinfectants, household cleaners, alcohol and drugs supposed to be effective in COVID-19 treatment protocols. ${ }^{20-22}$

The first case of COVID-19 in Jordan was confirmed on 2 March 2020. The Jordanian government announced a national lockdown that came into effect on 21 March 2020 and continued through to 21 May 2020. During this lockdown, there was a stay-at-home order with the suspension of all social, religious and work activities except for a few hours of window period each day allowing people to buy their essential goods. ${ }^{23}$ We conducted this study to evaluate if the lockdown has led to any change in the incidence or pattern of toxic exposures or poisoning in Jordan, especially those associated with cleaners, hand sanitisers and alcohol. This study will analyse the patterns of toxic exposures and poisoning among the Jordanian population during the COVID-19 lockdown as compared with the exact period of the previous year.

\section{METHODS}

\section{Data source}

There are three poison centres in Jordan: Jordanian Royal Medical Services Poison Center, Jordan University Hospital Poison Center and Pharmacy One Poison Center. Each of these centres works independently and there is no central reporting system. All three centres receive calls directly from healthcare workers and the public; however, Pharmacy One Poison Center is the only one responsible for receiving calls related to poisoning from the Civil Defense Directorate (CDD), the primary emergency response service in Jordan (911). The directorate is compelled by the law to report poisoning incidences to the poison centre as soon as the command centre receives the report, and reporting is near real time. Therefore, we decided to study data from the Pharmacy One Poison Center because it is the only one responsible for responding to the CDD calls.

Pharmacy One Poison Center is a large non-profit national poison centre that receives unrestricted calls from the public, healthcare workers and CDD calls (911), runs for 24 hours per day, over 7 days a week, and provides free professional advice and management information regarding toxic exposures and poisoning.

\section{Poisoning reporting system}

Cases are reported to the poison centre through the direct hotline or directed via the CDD command centre. Poison centre specialists will respond to the caller over the phone. Information about the patient demographics such as age, gender, residence, information about the poisoning incident (time of exposure, involved agent, single or multiple agents, dose, site, route), and the nature of symptoms, if found, were collected using open direct questions, and data directly transformed into a preformed database.
Based on the American Association of Poison Control Centers guidelines, poisoning cases are categorised into drugs, hydrocarbons, pesticides, gases, household products, heavy metals, bites and stings (insects, scorpions, snakes), and plant or food exposures. ${ }^{24}$ Severity is classified into five classes based on Poisoning Severity Score (PSS) described by Persson and colleagues. ${ }^{25}$ Grades 0 and 1 include patients who develop either no or mild symptoms of poisoning (non-toxic exposures, subtoxic exposures, asymptomatic exposures, or prolonged time after exposure $>24$ hours with no signs or symptoms) are advised for home observation or symptomatic home treatment. Grades 2, 3 and 4 include patients who develop moderate-to-severe symptoms or die (exposures with a known toxic agent, patients who developed moderateto-severe symptoms, exposures exceeding safe doses) are directed to the hospital. Clinical information and advice about poisonous agents, safe doses, first-aid actions, and home treatment protocols are obtained from the MICROMEDEX POISINDEX toxicology information database and in-house databases containing information about prevalent poisonous agents accounting for poisoning in our country. ${ }^{26}$

\section{Data collection}

The electronic records of Pharmacy One Poison Center were revised for the period (21 March 2020-21 May 2020). All calls related to toxic exposures or poisoning were included. In addition, all calls for the same period during 2019 (21 March 2019-21 May 2019) were included. For each case, data about the call source (general public, healthcare worker or CDD calls (911)), demographic data (age, gender), data about exposure (type, site, route and reason of exposure) and medical outcome were collected. The medical outcome was classified based on PSS. PSS provides a standardised scale for grading the severity of acute poisoning based on observed signs and symptoms. We chose to use PSS because not only is it simple, based on clinical symptoms and signs, but it can also be used for both children and adults. The classification of poisoning using PSS can be made regardless of the type and number of toxic agents. It is also possible to prevent underestimation as the severity is concluded by the most severe symptoms and signs.

\section{Data analysis}

The database was established using Microsoft Excel 2016. Descriptive analysis, statistical procedures and graphs were done using the Data Analysis tool pack, an add-in feature on Microsoft Excel 2016. Percentages of change in exposure were calculated based on the following equation:

$$
\% \text { of } \Delta=\left(\frac{\text { Percentage during Lockdown }- \text { Percentage during } 2019}{\text { Percentage during } 2019}\right) \times 100 \%
$$

\section{Patient and public involvement}

Patients or the public were not involved in the design, conduct, reporting or dissemination plans of this study. 


\section{RESULTS}

During the COVID-19 lockdown from 21 March to 21 May 2020, Pharmacy One Poison Center received a total of 544 calls related to toxic exposures, which represents a $91 \%$ increase in the number of calls during the same period in 2019 ( $\mathrm{n}=285$ calls). Drug exposure calls ranked first with a total of 321 calls (59\% of total calls), followed by household cleaners (83 calls, $15 \%$ of total calls) and alcohol exposure (37 cases, $7 \%$ ). Toxic gases (eight cases, $1 \%$ ) and toxic plants (one case, $<1 \%$ ) were among the least reported exposures. Notably, exposures related to toxic gases, alcohol, domestic animal bites, household cleaners, and drugs increased by 300\%, 208\%, 175\%, $159 \%$, and $128 \%$, respectively; in contrast, exposures related to snake bites, scorpion stings, and toxic plants decreased by $100 \%, 55 \%$, and $50 \%$, respectively (table 1 , figure 1).

The most prevalent route of exposure was ingestion with 446 cases (82\%), followed by dermal (56 cases, $10 \%$ ). Compared with 2019, there was a notable rise in ocular exposures $(550 \%$ increase; 13 cases in 2020 compared with 2 cases in 2019), ingestion exposures (increased by $104 \%$; 446 cases in 2020 compared with 219 cases in 2019 ) and inhalational exposures (50\% increase; 18 cases in 2020 compared with 12 in 2019) (table 1, figure 2). Most exposures occurred at home (528 cases, 97\%). While home exposures increased by $103 \%$, outdoor, work, and school exposures decreased by $26 \%, 60 \%$, and $100 \%$, respectively (table 1 , figure 3 ).

As of the reason and motive of exposure, unintentional exposures in the lockdown constitute $75 \%$ of exposures (406 cases), followed by therapeutic, suicidal and intentional exposures ( 35 cases, 33 cases, 31 cases, respectively, $6 \%$ each). There was a marked increase in intentional exposures by $933 \%$ ( 3 cases in 2019, 31 cases in lockdown), medical errors by $175 \%$ ( 8 cases in 2019,22 cases in lockdown) and unintentional exposures by $142 \%$ (168 cases in 2019, 406 cases in lockdown). On the other hand, occupational exposures (9 cases in 2019, 0 cases in lockdown), bites and stings (31 cases in 2019, 3 cases in lockdown), and suicidal exposures (36 cases in 2019, 33 cases in lockdown) decreased by $100 \%, 90 \%$, and $8 \%$, respectively (table 1 , figure 4 ).

Fifty-seven per cent (310 cases) of the exposures occurred in males, and 43\% (243 cases) occurred in females. Males reported more drug exposures. In contrast, females reported more alcohol exposures. Males reported a drastic increase in exposures related to household cleaners by $236 \%$ vs $100 \%$ increase for females. Females reported an increase in alcohol exposure by $243 \%$ vs $160 \%$ for males. The exposure to toxic gases was the same when comparing genders, both increasing by $300 \%$ (table 1, figure 5). Exposures were reported in all age groups, with children from 0 to 5 years being the most affected by $61 \%$ of the cases (332 cases). The age group from 11 to 15 years reported the sharpest increase in exposures by $275 \%$, followed by age group over 50 years by $143 \%$ increase (table 1 , figure 6 ).
There were 292 (54\%) calls from CDD (911), 156 (29\%) calls from the general public, and $96(18 \%)$ calls from healthcare workers, with an increase of $170 \%, 68 \%$, and $14 \%$, respectively (table 1 , figure 7 ).

Lastly, based on the PSS, 37\% (201 cases) of the cases subsided with no effects, $42 \%$ (228 cases) with minor effects, $17 \%$ (90 cases) with moderate effects, $5 \%$ (25 cases) with severe effects and no deaths were reported. Ten per cent (54 cases) needed hospital admissions. Forty-one per cent of total emergency service calls were closed only based on poison centre advice, with no reported adverse outcomes. The number of cases resolved with no or minor effects increased by $673 \%$ and $140 \%$, respectively, and those with moderate or severe effects decreased by $31 \%$ and $24 \%$, respectively. The total number of admissions increased by $260 \%$ (15 cases in 2019 compared with 54 cases in lockdown), and admissions for children from 0 to 5 years increased by $329 \%$ ( 7 cases in 2019 compared with 30 cases in lockdown). The emergency services dispatch rate decreased by $33 \%$ (table 1 , figure 8 ).

\section{DISCUSSION}

Our study showed that lockdown resulted in a $91 \%$ increase in calls related to toxic exposures as well as a pattern change compared with the previous year. Poison centres have also reported similar results in the USA, Canada and France. ${ }^{13-15}$ We did not find an apparent reason for such an increase. However, Le Roux and colleagues suggest a possible explanation for this rise is the behavioural modifications caused by fear of coronavirus, including excessive house cleaning and misuse of cleaning products for personal hygiene or food sanitation. ${ }^{16}$ Another additional factor is the decrease in cognitive performance and decision-making induced by isolation measures, combined with an increased impulsivity contributing to such an increase. ${ }^{16}$ Chang and colleagues ascribe such an increase to the cleaning recommendations and guidelines issued by many healthcare agencies and social media. ${ }^{13}$

Our study showed an increase in exposures related to toxic gases, alcohol, household cleaners, drugs and domestic animal bites. Toxic gas exposure includes the well-described chlorine gas that results from mixing bleach and other household chemicals. ${ }^{16}$ Notably, guidelines disseminated in the early days of the pandemic as a part of public infection-control campaigns have led to the misuse of alcohol-based hand sanitisers and household cleaners. ${ }^{13}{ }^{14}$ Reportedly, disinfectants erroneously used to disinfect vegetables, and alcohol-based hand sanitisers applied to the whole body resulting in burns, or the use of highly concentrated sodium hypochlorite are examples of how people falsely interpret these campaigns. ${ }^{16}$ Canadian poison centres have also reported similar increases in exposures to bleaches, hand sanitisers, disinfectants, chlorine and chloramine gas. ${ }^{14}$

The Jordanian society is mainly conservative, and thereby the use and consumption of drinking alcohol 
Table 1 Incidence and patterns of toxic exposures and poisoning among Jordanian population during COVID-19 lockdown and 2019 (March-May)

\begin{tabular}{|c|c|c|c|}
\hline & \multirow{2}{*}{$\begin{array}{l}2019 \\
\text { Number of cases }\end{array}$} & \multicolumn{2}{|c|}{ COVID-19 lockdown } \\
\hline & & Number of cases & $\%$ of $\Delta$ \\
\hline Total number of cases & 285 & 544 & 91 \\
\hline \multicolumn{4}{|l|}{ Class of exposure } \\
\hline Drugs & $141(49 \%)$ & $321(59 \%)$ & 128 \\
\hline Household cleaners* & $32(11 \%)$ & $83(15 \%)$ & 159 \\
\hline Alcohol $^{*}$ & $12(4 \%)$ & $37(7 \%)$ & 208 \\
\hline Pesticides & $20(7 \%)$ & $20(4 \%)$ & 0 \\
\hline Hydrocarbons* & $16(6 \%)$ & $17(3 \%)$ & 6 \\
\hline Food & $17(6 \%)$ & $14(3 \%)$ & -18 \\
\hline Insect bites & $14(5 \%)$ & $15(3 \%)$ & 7 \\
\hline Domestic animal bites* & $4(1 \%)$ & $11(2 \%)$ & 175 \\
\hline Heavy metals & $9(3 \%)$ & $12(2 \%)$ & 33 \\
\hline Toxic gases (chlorine) ${ }^{\star}$ & $2(1 \%)$ & $8(1 \%)$ & 300 \\
\hline Scorpion stings & $11(4 \%)$ & $5(1 \%)$ & -55 \\
\hline Snake bites & $5(2 \%)$ & $0(0 \%)$ & -100 \\
\hline Toxic plants & $2(1 \%)$ & $1(0 \%)$ & -50 \\
\hline \multicolumn{4}{|l|}{ Route of exposure } \\
\hline Ingestion & $219(77 \%)$ & $446(82 \%)$ & 104 \\
\hline Inhalation & $12(4 \%)$ & $18(3 \%)$ & 50 \\
\hline Dermal & $46(16 \%)$ & $56(10 \%)$ & 22 \\
\hline Parenteral & $3(1 \%)$ & $3(1 \%)$ & 0 \\
\hline Ocular & $2(1 \%)$ & $13(2 \%)$ & 550 \\
\hline Others $^{*}$ & $3(1 \%)$ & $8(1 \%)$ & 167 \\
\hline \multicolumn{4}{|l|}{ Site of exposure } \\
\hline Work & $5(2 \%)$ & $2(0 \%)$ & -60 \\
\hline Outdoor & $19(7 \%)$ & $14(3 \%)$ & -26 \\
\hline Home & $260(91 \%)$ & $528(97 \%)$ & 103 \\
\hline School & $1(0 \%)$ & $0(0 \%)$ & -100 \\
\hline \multicolumn{4}{|l|}{ Reason of exposure } \\
\hline Suicidal & $36(13 \%)$ & $33(6 \%)$ & -8 \\
\hline Unintentional & $168(59 \%)$ & $406(75 \%)$ & 142 \\
\hline Occupational & $9(3 \%)$ & $0(0 \%)$ & -100 \\
\hline Medical consultation* & $14(5 \%)$ & $14(3 \%)$ & 0 \\
\hline Therapeutic* & $16(6 \%)$ & $35(6 \%)$ & 119 \\
\hline Intentional & $3(1 \%)$ & $31(6 \%)$ & 933 \\
\hline Medical error & $8(3 \%)$ & $22(4 \%)$ & 175 \\
\hline Bite/sting & $31(11 \%)$ & $3(1 \%)$ & -90 \\
\hline \multicolumn{4}{|l|}{$\begin{array}{l}\text { Distribution by age groups } \\
\text { (years) }\end{array}$} \\
\hline $0-5$ & $142(50 \%)$ & $332(61 \%)$ & 134 \\
\hline $6-10$ & $18(6 \%)$ & $29(5 \%)$ & 61 \\
\hline $11-15$ & $4(1 \%)$ & $15(3 \%)$ & 275 \\
\hline $16-20$ & $15(5 \%)$ & $30(6 \%)$ & 100 \\
\hline $21-50$ & $92(32 \%)$ & $104(19 \%)$ & 13 \\
\hline
\end{tabular}

Continued 
Table 1 Continued

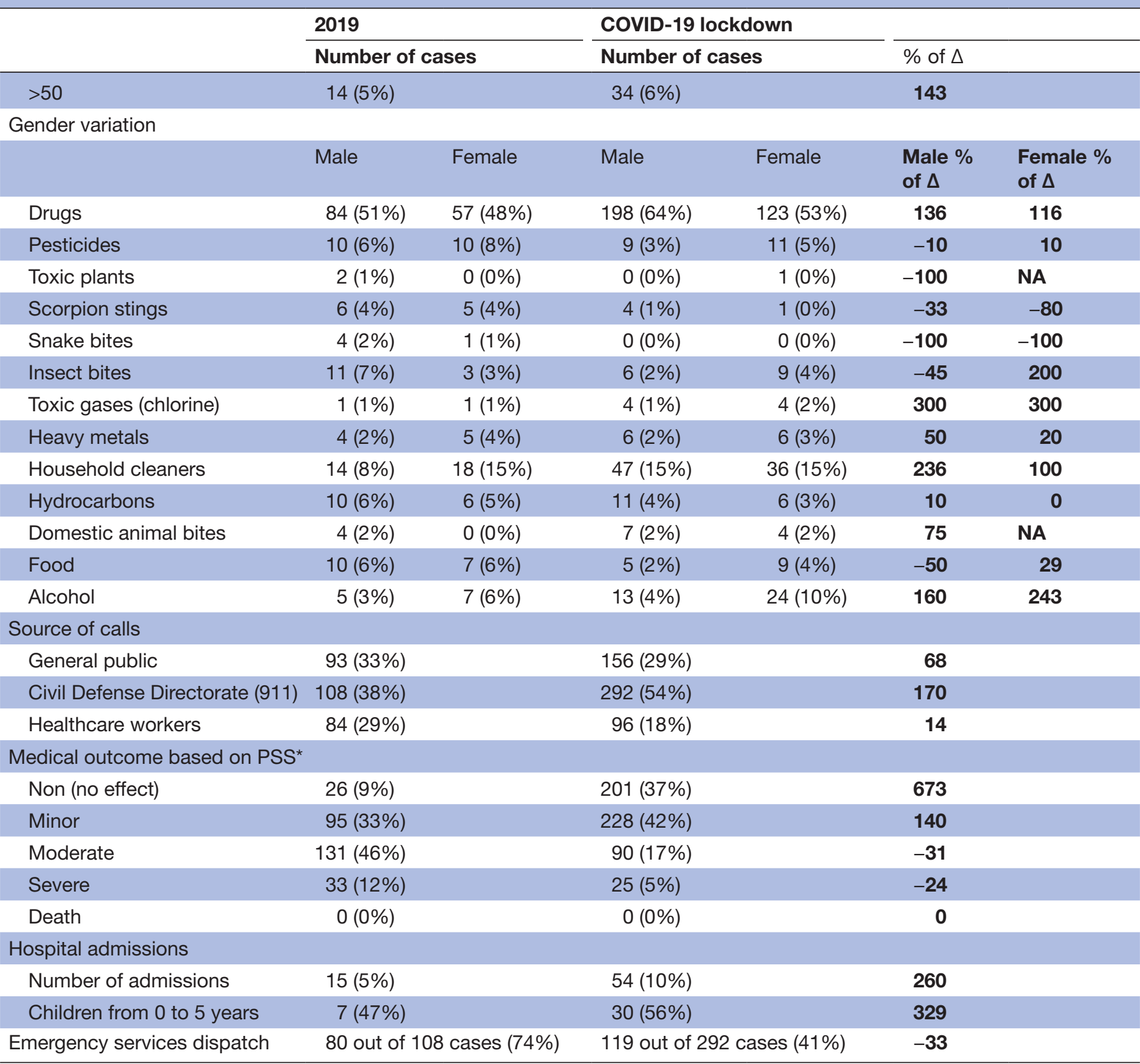

$\mathrm{n}(\%)$.

*Household cleaners: products containing ammonia, hydrochloric acid, sodium hypochlorite or alkaline cleaning products, drain and oven cleaners, etc). Alcohol: ethanol-based cleaning solutions, hand sanitisers or pure ethanol as spray (not for intake). Hydrocarbons: mainly paint thinners and kerosene. Domestic animal bites: from dogs, cats and hamsters. Toxic gases: inhaled chlorine. Other routes of exposure include: rectal and unknown routes. Medical consultation: only reported consultations without reports of toxicity. Therapeutic reasons include: incidents reported as side effects of medication and drugs.

NA, not applicable (mathematical causes); PSS, Poisoning Severity Score.

is limited. As a result, there were no reported cases of poisoning due to drinking alcohol (ethanol or methanol). However, in countries such as the USA and Russia, stockpiling and consumption of alcohol increased as well as the misuse of alcohol-containing agents. ${ }^{27}{ }^{28} \mathrm{In}$ the UK, it is predicted to witness a spike in alcohol misuse with frequent relapses in addicted individuals as the increase in consumption might be related to stress and impulsivity associated with self-isolation measures. ${ }^{29}$ In addition, ingestion of methanol-containing hand sanitisers has led to the demise of consumers in many countries such as the USA and Iran. ${ }^{19}{ }^{21}$ In fact, the numbers of methanol poisoning-related deaths are the largest in Iran's history as it was more prevalent than COVID-19-related deaths in some Iranian provinces. ${ }^{19}$ The spread of misleading messages through social media regarding alcohol use as 


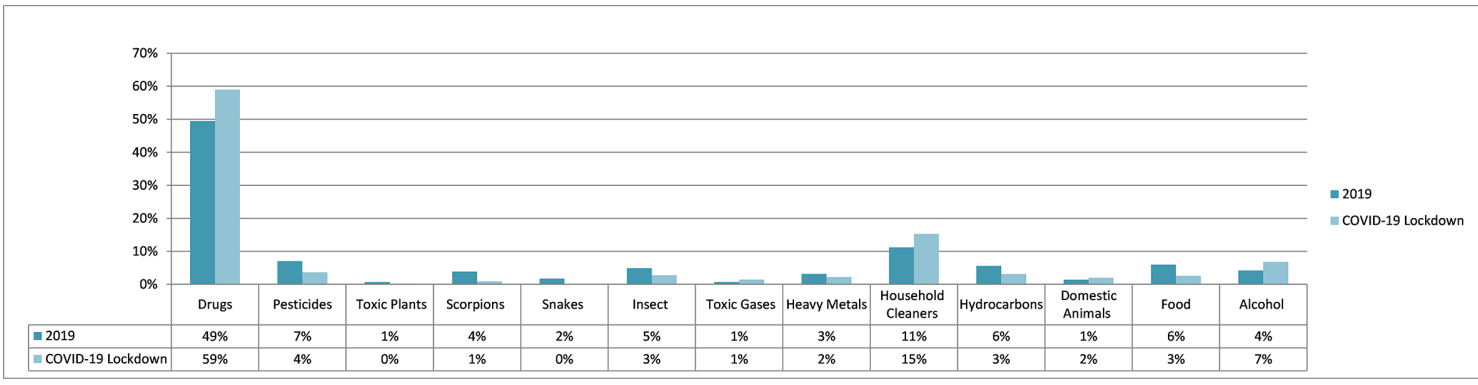

Figure 1 Class of exposure. This chart shows the difference in classes of exposure when comparing the period of 2019 with COVID-19 lockdown.

a protective agent against COVID-19 and, in the case of Iran, sanctions on alcohol imports are one of the many reasons for such a spike in methanol consumption. ${ }^{19} 21$ As a result, a multitude of countries has banned alcohol sale to limit the consequences of alcohol-related health emergencies on the healthcare system. ${ }^{28}$

Exposures to drugs in our study were primarily observed in children. A possible explanation for such an observation is that families stocked drugs anticipating shortages, along with stay-at-home policy; children spent more time at home, increasing their accidental exposure to such drugs. ${ }^{16}$ This contradicts reports from France, where a fall in drug exposures was noted, which was linked to the fall in suicidal attempts by drugs. ${ }^{16}$ No reported cases of exposures due to drugs used in COVID-19 treatment. Also, no cases of opioid poisoning or poisoning due to recreational drugs were reported to our centre. However, the global prevalence of the aforementioned poisoning incidences is conflicting in its nature. The average weekly death rate increased in Canada by $38 \%$ in the first 15 weeks of COVID-19 compared with the 15 weeks before. ${ }^{30}$ In the USA, the pandemic has brought a probable surge in adverse effects related to overdosing. ${ }^{31}{ }^{32}$ The European Monitoring Centre for Drugs and Drug Addiction reported $50 \%$ decrease in illicit drug use in European countries. ${ }^{33}$ Le Roux and colleagues reported a decrease in recreational drug use in France, and it was suggested that such a decrease is due to fewer opportunities to use such drugs, reduced availability of illicit drugs to

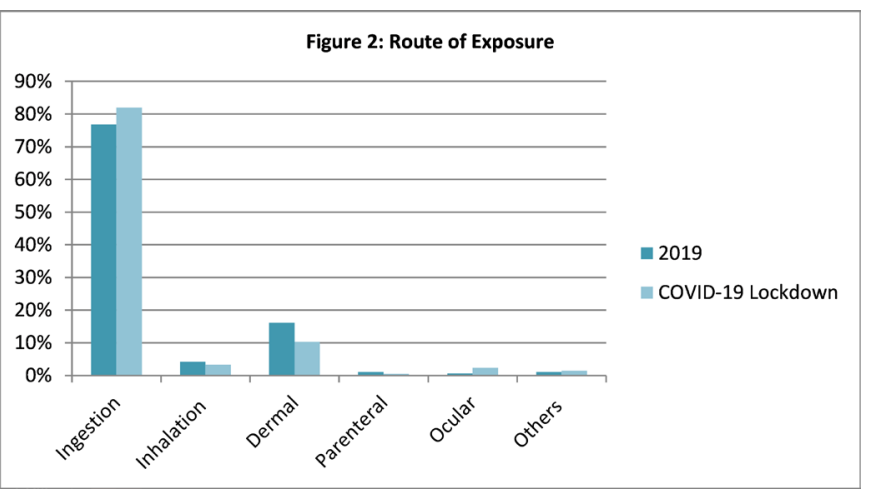

Figure 2 Route of exposure. This chart shows changes in routes of exposure in both studied periods. buy, reduced ability to collect them and loss of available income to buy it. ${ }^{16}$

We noted an increase in bites related to domestic animals. Similarly, Dixon and Mistry described a threefold rise in paediatric emergency room (ER) visits due to dog bites during the stay-at-home lockdown policy, owing such observation to decreased adult supervision over children, and increased dog stress because of confinement. ${ }^{34}$ On the other hand, we noticed fewer snake bites, scorpion stings, toxic plant exposures and occupational exposures, as home internment and weather conditions averted such exposures.

Our study showed increased exposure in all age groups, but a remarkable observation was the high increase in exposure in the adolescents (11-15 years) group. It is possible that even though this age group understands what these chemicals are used for, they have little awareness about the potential toxicity. Other similar studies showed different age group observations. For example, the French poison centre reported an increase in exposure in all age groups except 5-25 years group, and the most significant increase occurred in patients over 65 years. ${ }^{16}$ Likewise, the Canadian poison centre did not notice an increase in exposure in those below the age of 19 years. ${ }^{14}$ In fact, children below 5 years represented a large percentage of calls received during the study period. This might be due to the closure of schools and kindergartens, with children spending more time at home, and

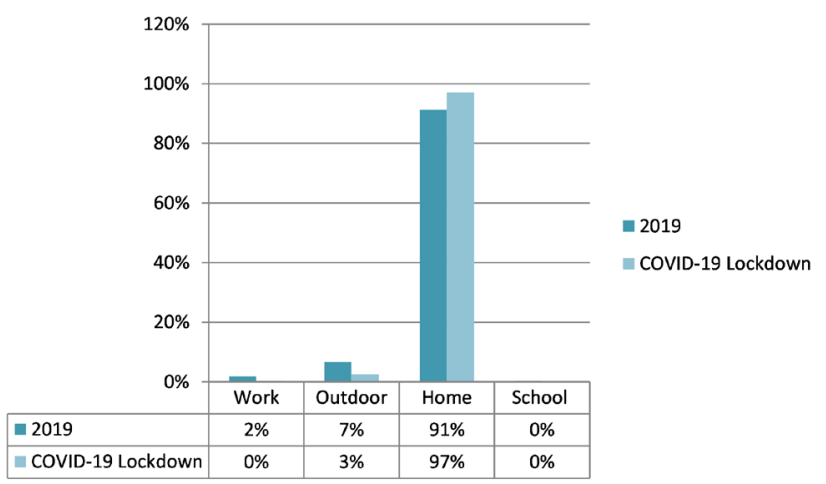

Figure 3 Site of exposure. In this chart, changes in sites of exposure are shown. 


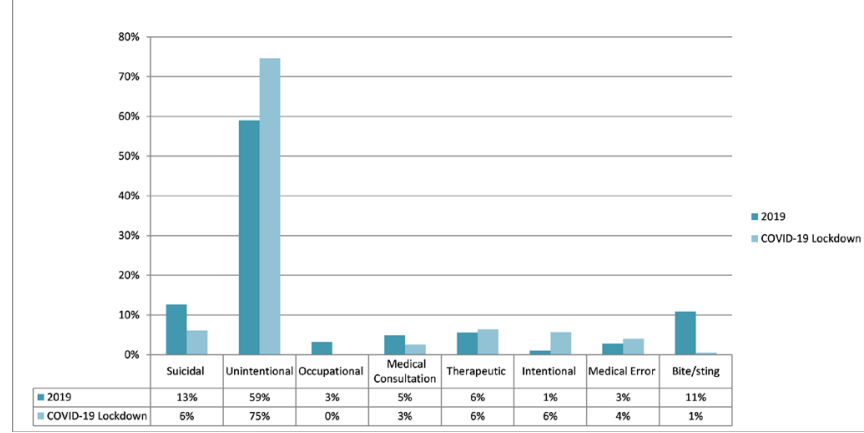

Figure 4 Reason of exposure. Reasons for exposure for both periods are set side by side, showing variance.

therefore they have more chance for exposure. ${ }^{16}$ Furthermore, teleworking and homeschooling for older children contributed to such an increase by shifting parents' attention away from younger children. ${ }^{16}$

Among routes of exposure, the ocular route recorded the sharpest increase. This observation may be due to the fact that eyes are involved in chemical exposure, whether by accidental spraying of the eyes or touching the eyes after hand or face sanitation or via exposure to vapours. A study from the USA found that inhalational route observed the highest increase during the lockdown. ${ }^{13}$

While intentional exposures increased during the lockdown, we suggest that the increase was due to attempts to protect from acquiring infection. A Canadian poison centre reported a similar observation. ${ }^{14}$ Oppositely, we have noticed that suicidal exposures during the lockdown have decreased. This fall could be arguably due to the social and family support created by the stay-athome order. A French poison centre reported a similar observation. ${ }^{16}$

We noted an increase in calls from healthcare workers. Oppositely, this increase was accompanied by a fall in the proportion of severe cases despite the increase in hospital admission. The French poison centre reported similar findings. ${ }^{16}$ There is no palpable cause for such a decrease; however, under-reporting plays a role as it was the responsibility of the CDD during the lockdown, which might be overwhelming and could lead to under-reporting. Another possibility is related to the change in the pattern of poisoning during the lockdown resulting in fewer severe and fatal exposures. Severe cases in Jordan have

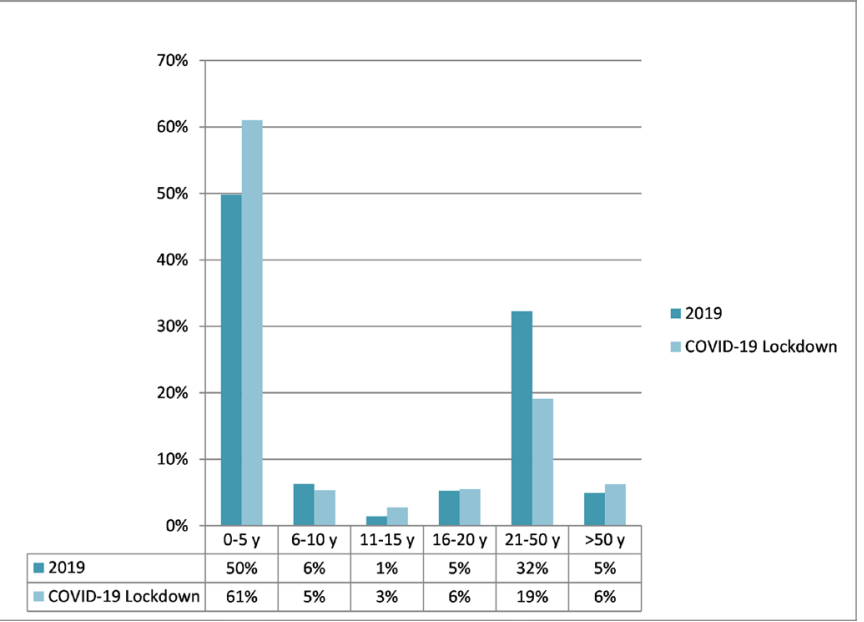

Figure 6 Distribution across age groups. In this chart, a correlation between different exposure classes and gender is highlighted.

been previously described as caused by animal bites and stings, toxic plants and food.$^{35}$ Our study shows that there has been a significant decrease in the above-mentioned agents during the lockdown. It is also important to mention the decrease in the number of suicide attempts using poisonous agents and efforts to increase awareness about early reporting of toxic exposures by the healthcare authorities.

A previous retrospective study reported 1992 cases of acute poisoning in Jordan between 2014 and 2018, with an average of 498 cases per year. The most commonly reported agents were drugs, household chemicals, and animal bites and stings. The male gender was more prevalent than females, and children were the most commonly affected groups. The majority of cases were reported to occur at home, and ingestion was the most common route. Furthermore, most exposures were unintentional, and the majority of cases were mild, with no deaths reported. Therefore, when comparing the previously mentioned study with our control period of MarchMay 2019, we cannot describe significant changes in the pattern of poisoning incidences. ${ }^{35}$

This study has its strength and limitations. Our data represent the majority of calls related to toxic exposures in Jordan, as Pharmacy One Poison Center is the only

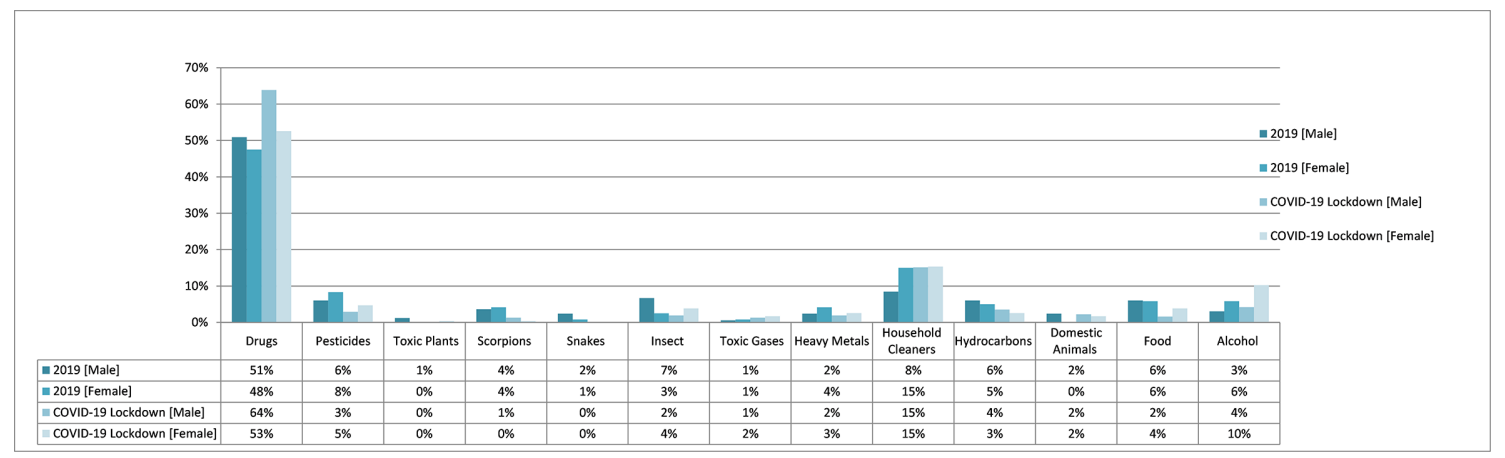

Figure 5 Gender variation. This chart shows the prevalence of toxic exposures across different age groups. 


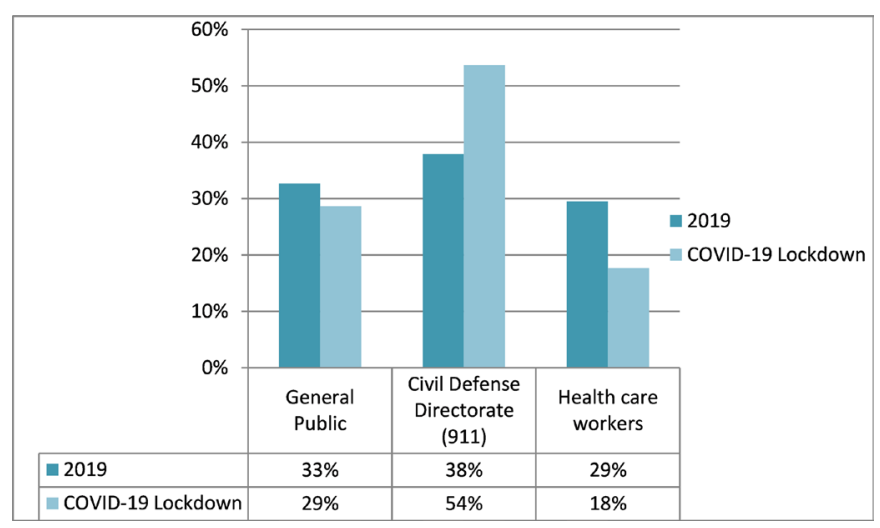

Figure 7 Source of calls. This chart shows the difference in the source of calls in both studied periods.

centre responsible for responding to calls from CDD, the primary emergency response service in Jordan (911). It also receives calls unrestrictedly from the public and healthcare workers at all times. However, this study has its limitations. Not all exposures were reported to the poison centre, because many were treated at home or sought direct medical help without notifying the poison centre. Furthermore, severely intoxicated or dead people usually arrive directly at the hospital without reporting the incidence to any poison centre. In addition, poisoning specialists make their judgement and management recommendations based on the caller's information. Some cases were closed by simple advice over the phone without on-site confirmation of the nature of exposure. Lastly, there were difficulties accessing data from other poison centres.

In conclusion, there is a change in both the number and pattern of toxic exposure-related calls during the lockdown, mostly due to fear of coronavirus. Exposures related to toxic gases, alcohol, household cleaners, drugs and domestic animal bites have increased, whereas exposures related to snake bites, scorpion stings, toxic plants and occupational exposures have decreased. This observed increase in calls involved all age groups, with children below 5 years accounting for the largest percentage. Ocular exposures showed the sharpest increase among all exposure routes. While intentional exposures showed a remarkable increase, those exposures were not of suicidal

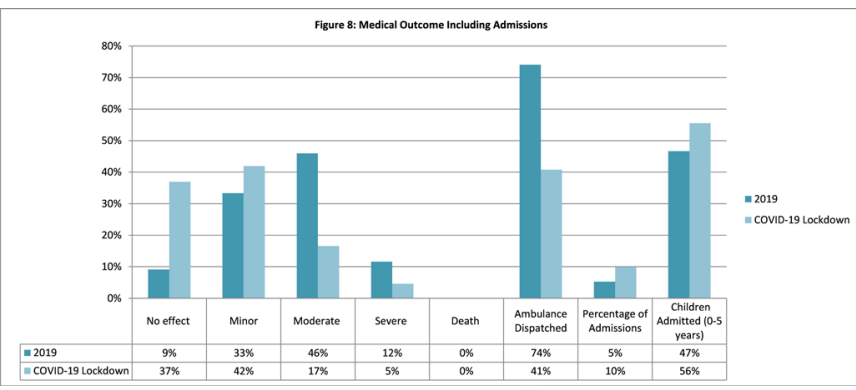

Figure 8 Medical outcome including admissions. Changes in medical outcomes are shown in this chart. It also includes changes in the percentage of admissions and percentage of children admitted during both periods. nature. In fact, our study showed a decrease in suicidal exposures. In addition, calls from healthcare workers have increased, as well as case severity, while hospital admission rate increased. This study highlights the important role of poison centres, as they help decrease the burden on healthcare facilities. At poison centres, specialists respond to calls and triage the patients based on case severity to set an appropriate treatment plan. This alleviates unnecessary use of ambulances and saves ER resources for severe cases. Furthermore, specialists at poison centres are consulted by healthcare workers, thereby saving the cost of unwarranted patient transfer, investigations, laboratory work-up, and, most importantly, evading case progression and complications. Poison centres can be referenced for evidence-based protocols, and the length of stay can be curtailed. Information about routes and types of exposures provided by poison centres is also valuable when setting healthcare policies.

Contributors LR, HMD, KA and AIA-F-conceptualisation and study design. LR and HMD - project administration. AIA-F-data collection. NHH and HMD—literature search and review. HMD—draft of the initial manuscript. LR, HMD, MD and SAA edited and wrote the final manuscript. All authors read, edited, proofread and approved the final manuscript before submission. LR is the responsible author.

Funding The authors have not declared a specific grant for this research from any funding agency in the public, commercial or not-for-profit sectors.

Competing interests None declared.

Patient and public involvement Patients and/or the public were not involved in the design, or conduct, or reporting, or dissemination plans of this research.

Patient consent for publication Not required.

Ethics approval According to IRB policy at our institution, this study is exempted from review and approval, as it is a retrospective review of records, and the personal information has been recorded anonymously where subjects cannot be identified directly or indirectly, and the investigators do not need to contact the subjects involved. We also took consent for data collection and records review.

Provenance and peer review Not commissioned; externally peer reviewed.

Data availability statement Data are available upon reasonable request. Data used in this study are available upon request. We obtain the formal permission for data use in this research. Data do not contain any patients' data or identifiers.

Open access This is an open access article distributed in accordance with the Creative Commons Attribution Non Commercial (CC BY-NC 4.0) license, which permits others to distribute, remix, adapt, build upon this work non-commercially, and license their derivative works on different terms, provided the original work is properly cited, appropriate credit is given, any changes made indicated, and the use is non-commercial. See: http://creativecommons.org/licenses/by-nc/4.0/.

\section{ORCID iDs}

Liqaa Raffee http://orcid.org/0000-0001-8020-8677

Khaled Alawneh http://orcid.org/0000-0003-4391-725X

Moath Darweesh http://orcid.org/0000-0002-5413-7120

Sami A Almasarweh http://orcid.org/0000-0002-6824-6483

\section{REFERENCES}

1 Zhu N, Zhang D, Wang W, et al. A novel coronavirus from patients with pneumonia in China, 2019. N Engl J Med 2020;382:727-33.

2 Adhanom T. WHO Director-General's opening remarks at the media briefing on COVID-19-16 March 2020; 2020. World Health Organization. Available: https://www. who. int/dg/speeches/detail/ who-director-general-s-opening-remarks-at-themedia-briefing-oncovid-19-11-march-2020

3 Fisher D, Wilder-Smith A. The global community needs to swiftly ramp up the response to contain COVID-19. Lancet 2020;395:1109-10. 
4 Eubank S, Eckstrand I, Lewis B, et al. Commentary on Ferguson, et al., "Impact of Non-pharmaceutical Interventions (NPIs) to Reduce COVID-19 Mortality and Healthcare Demand". Bull Math Biol 2020;82:52.

5 Wilder-Smith A, Freedman DO. Isolation, quarantine, social distancing and community containment: pivotal role for old-style public health measures in the novel coronavirus (2019-nCoV) outbreak. J Travel Med 2020;27:1-4.

6 Anderson RM, Heesterbeek $\mathrm{H}$, Klinkenberg D, et al. How will countrybased mitigation measures influence the course of the COVID-19 epidemic? Lancet 2020;395:931-4.

7 Lau H, Khosrawipour V, Kocbach P, et al. The positive impact of lockdown in Wuhan on containing the COVID-19 outbreak in China. $J$ Travel Med 2020;27:taaa037.

8 Zarocostas J. How to fight an infodemic. Lancet 2020;395:676.

9 Depoux A, Martin S, Karafillakis E, et al. The pandemic of social media panic travels faster than the COVID-19 outbreak. J Travel Med 2020;27:taaa031.

10 Gottlieb M, Dyer S, Information DS. Information and disinformation: social media in the COVID-19 crisis. Acad Emerg Med 2020;27:640-1.

11 The Lancet Infectious Diseases. The COVID-19 infodemic. Lancet Infect Dis 2020;20:875.

12 Galvão J. COVID-19: the deadly threat of misinformation. Lancet Infect Dis 2021;21:e114.

13 Chang A, Schnall AH, Law R, et al. Cleaning and Disinfectant Chemical Exposures and Temporal Associations with COVID-19 - National Poison Data System, United States, January 1, 2020-March 31, 2020. MMWR Morb Mortal Wkly Rep 2020;69:496-8.

14 Yasseen III A, Weiss D, Remer S, et al. Increases in exposure calls related to selected cleaners and disinfectants at the onset of the COVID-19 pandemic: data from Canadian poison centres. Health Promot Chronic Dis Prev Can 2021:1:25-9.

15 Le Roux G, Sinno-Tellier S, et al, French Poison Control Centre members. COVID-19: home poisoning throughout the containment period. Lancet Public Health 2020;5:e314.

16 Le Roux G, Sinno-Tellier S, Puskarczyk E, et al. Poisoning during the COVID-19 outbreak and lockdown: retrospective analysis of exposures reported to French poison control centres. Clin Toxicol 2021;59:832-9.

17 Richards GC. Alcohol-Based hand sanitisers: a warning to mitigate future poisonings and deaths. BMJ Evid Based Med 2021;26:65-8.

18 Wong A. COVID-19 and toxicity from potential treatments: panacea or poison. Emerg Med Australas 2020;32:697-9.

19 Delirrad M, Mohammadi AB. New methanol poisoning outbreaks in Iran following COVID-19 pandemic. Alcohol Alcohol 2020;55:347-8.

20 Yip L, Bixler D, Brooks DE, et al. Serious Adverse Health Events, Including Death, Associated with Ingesting Alcohol-Based Hand Sanitizers Containing Methanol - Arizona and New Mexico, MayJune 2020. MMWR Morb Mortal Wkly Rep 2020;69:1070-3.
21 Clay JM, Parker MO. Alcohol use and misuse during the COVID-19 pandemic: a potential public health crisis? Lancet Public Health 2020;5:e259.

22 Chary MA, Barbuto AF, Izadmehr S, et al. COVID-19: therapeutics and their toxicities. J Med Toxicol 2020;16:284-94.

23 Defence Order No. (2) [Internet]. Pm.gov.jo, 2021. Available: http:// www.pm.gov.jo/upload/files/Order-Defense-2.pdf

24 Bronstein AC, Spyker DA, Cantilena LR, et al. 2007 Annual Report of the American Association of Poison Control Centers' National Poison Data System (NPDS): 25th Annual Report. Clin Toxicol 2008;46:927-1057.

25 Persson HE, Sjöberg GK, Haines JA, et al. Poisoning severity score. Grading of acute poisoning. J Toxicol Clin Toxicol 1998;36:205-13.

26 Detailed Toxicology Information From POISINDEX [Internet]. Available: https://www.micromedexsolutions.com/micromedex2/4. 77.0/WebHelp/Document_help/Toxicology_Management_document. htm [Accessed 02 Sep 2021].

27 Pollard MS, Tucker JS, Green HD. Changes in adult alcohol use and consequences during the COVID-19 pandemic in the US. JAMA Netw Open 2020;3:e2022942.

28 Neufeld M, Lachenmeier DW, Ferreira-Borges C, et al. Is Alcohol an "Essential Good" During COVID-19? Yes, but Only as a Disinfectant! Alcohol Clin Exp Res 2020;44:1906-9.

29 PHE. Monitoring alcohol consumption and harm during the COVID-19 pandemic, 2021. Available: https://assets.publishing. service.gov.uk/government/uploads/system/uploads/attachment_ data/file/1002627/Alcohol_and_COVID_report.pdf

30 The Ontario Drug Policy Research Network, The Office of the Chief Coroner for Ontario/Ontario Forensic Pathology Service, Public Health Ontario, Centre on Drug Policy Evaluation. Preliminary Patterns in Circumstances Surrounding Opioid-Related Deaths in Ontario during the COVID-19 Pandemic. 2020;(November):1-24. Available: https://www.publichealthontario.ca/-/media/documents/o/ 2020/opioid-mortality-covid-surveillance-report.pdf?la=en

31 Wainwright JJ, Mikre M, Whitley P, et al. Analysis of drug test results before and after the US Declaration of a national emergency concerning the COVID-19 outbreak. JAMA 2020;324:1674-7.

32 Wakeman SE, Green TC, Rich J. An overdose surge will compound the COVID-19 pandemic if urgent action is not taken. Nat Med 2020;26:819-20.

33 European Monitoring Centre for Drugs and Drug Addiction (EMCDDA). Impact of COVID-19 on patterns of drug use and drugrelated harms in Europe (Trendspotter briefing). 2020;(June):1-27. Available: https://www.emcdda.europa.eu/system/files/publications/ 13130/EMCDDA-Trendspotter-Covid-19-Wave-2_1.pdf

34 Dixon CA, Mistry RD. Dog bites in children surge during coronavirus Disease-2019: a case for enhanced prevention. J Pediatr 2020;225:231-2.

35 Albals D, Yehya A, Issa R, et al. Retrospective assessment of acute poisoning incidents by nonpharmaceutical agents in Jordan: data from pharmacy One ${ }^{\mathrm{TM}}$ poison call center, 2014 to 2018-Part I. Pharmacol Res Perspect 2020;8:e00582. 